\title{
Modelling the Climate Change on Crop Estimation in the Semi-Arid Region of Pakistan Using Multispectral Remote Sensing
}

\author{
Zeeshan Zafar ${ }^{1}$, Shoaib Farooq ${ }^{2}$, Muhammad Irfan Ahamad ${ }^{1,}$, Muhammad Sajid Mehmood ${ }^{1}$, \\ Nasir Abbas 1 , Summar Abbas ${ }^{3}$ \\ ${ }^{1}$ College of Urban and Environmental Sciences, Northwest University, Xi'an, China \\ ${ }^{2}$ Institute of Geo-Information and Earth Observation, Pir Mehr Ali Shah Arid Agriculture University, Rawalpindi, Pakistan \\ ${ }^{3}$ Geological Survey of Pakistan (GSP), Quetta, Pakistan
}

Email address:

mirfan230@hotmail.com (M. I. Ahamad)

${ }^{*}$ Corresponding author

\section{To cite this article:}

Zeeshan Zafar, Shoaib Farooq, Muhammad Irfan Ahamad, Muhammad Sajid Mehmood, Nasir Abbas, Summar Abbas. Modelling the Climate Change on Crop Estimation in the Semi-Arid Region of Pakistan Using Multispectral Remote Sensing. Optics.

Vol. 9, No. 1, 2020, pp. 1-7. doi: 10.11648/j.optics.20200901.11

Received: October 30, 2020; Accepted: November 23, 2020; Published: December 4, 2020

\begin{abstract}
Remote sensing (RS) is a tool in modern years for the monitoring of crops. Normalized Difference Vegetation Index (NDVI) derived from multi-temporal satellite imagery facilitates the analysis of vegetation growth stage, while comparing it with field/historical departmental yield data. Historical metrological data is also very useful in crop yield estimation especially in arid/semi-arid climatic zones. The metrological conditions including rainfall, humidity, sunshine, and temperature plays vital role in the growth and yield of crops; thus, the climatic conditions can adversely affect the crop yields if are not in accordance with growth requirement of a particular crop. Most of the agricultural land of Punjab province is in semiarid climatic zone including Chakwal, Jhelum, Mianwali, Khushab, Sargodha, Mandi Bahauddin, Gujranwala, Hafizabad, Shiekhupura, Nankana Sahib, Lahore, Kasur, Faislabad and Chiniot districts. The study will investigate the impact of climate change on wheat crop yields of Chakwal district using advanced RS techniques from 1990 to 2015. Image classification to determine arable and non-arable lands; estimation of changes in temperature using thermal bands of satellite imagery, comparison of historical NDVI profiles; use of climatic data along with nonspatial departmental data for crop yield estimation and drawing its relationship with climatic variables.
\end{abstract}

Keywords: Metrological Data, Remote Sensing, Crop Yield Estimation, Semi-arid, Chakwal

\section{Introduction}

Increase in agricultural production improved annual income and has positive influence on food supply in the local market this contributes in agricultural sustainability by improving agricultural practice. Pakistan is basically an agricultural country, primarily economy of Pakistan depends upon agriculture although its economy has observed significant variations over the past few years. Agriculture is considered as one of the leading sectors contributing in country's economy, $19.8 \%$ of the gross domestic product (GDP) came from agriculture and almost half of $(42.5 \%)$ the rural population is associated with agriculture sector [1].

Over the past two decades, the population in Pakistan has increased exponentially, and, this rapid growth has caused two major problems among many others, that include increased demand for food, and decrease in land available for agriculture. Food production, both in terms of higher productivity and improved nutrient quality, has not kept pace with the needs of the expanding human population, leading to alarming levels of food insecurity. Extreme weather conditions, such as floods and droughts, associated with climate shifts across the globe are projected to cause even greater adverse effects on the food supply [2].

Wheat is the main agricultural product which is grown on 
a large scale over a wide spectrum of climatic and soil conditions. Wheat production comprises about $9.9 \%$ of the total agricultural productivity and contributes $2.0 \%$ to GDP [3]. Nearly $80 \%$ of the farmers are directly involved with the wheat production and this crop covers $40 \%$ of the total cropped area in Pakistan [5].

Although agriculture has greater role in food security and economy, still the country is unable to realize that is real agricultural production potential as it is much below the production of most countries in the world [2]. There is also an enormous gap between actual crop yield and possible potential crop yield in Pakistan [11]. This obviously pointing to lack of use of available technologies, if farmer start using available technologies according to the recommendations this can increase the agriculture production considerably [10]. Therefore, this is dire need of time to use of science and latest technology in agriculture field. Remote sensing techniques and remotely sensed data is highly reliable to detect and predict the potential yield and effects of different factors on the potential yield [2].

The traditional approach of measuring the crop yield is based on ground visits or field surveys. This type of data is crucial since it provides thorough information, and because it embodies direct observations in a point of interest typically associated with high quality measurements. On the other hand, the modern approach is based on remotely sensed satellite-based vegetation index observations. Both approaches have their advantages and limitations, however, the integration of these techniques could lead to the accurate estimation of the crop yield. These two kinds of data complement each other in several ways in the yield estimation process. The evaluation of crop yield output often depends on the traditional data gathering techniques, which, while generally accurate at the point source, are time intensive, and susceptible to bias errors [1].

In many countries, the limited or late access to the available data inhibits the assertive actions that can be taken to prevent potential food shortages. The traditional structure operated by the provincial government for recording and archiving agricultural output is reliant on manual and timeconsuming ground data surveying in randomly sampled villages. The field survey observations from inaccessible areas are also not likely recorded. Most of the data are obtained from field surveys and enumeration methods, and data synthesis and assimilation are finalized several months after the harvest. Hence, the application of such data for prompt decision-making and satisfactory planning for wheat surplus or shortages is often limited [7]. This is especially true if information and communication technology is not sufficiently advanced to disseminate timely information for decision makers [8]

In contrast to this, remotely sensed satellite data provide timely coverage to large areas even to those regions where the ground survey is not possible. The evolution in remote sensing and the availability of real-time satellite imagery have provided wide access to spatial variability of the earth features [4]. Satellite data have the potential to identify not only the crop types but also the crop yield estimates. Hence, remote sensing can be used to monitor and detect crop growth stages and to predict crop yield. The phonological stages and the crop health can be identified through the spectral responses of the crop by using multi-spectral data.

Impact of climatic change on crop growth and yield has been a hot topic all over the world in current time due to rapidly changing behavior of climate and food shortage all over the world. Technically in natural science, there are two methods to estimate the potential impacts of climate change on agricultural systems:

1 Use crop simulation models (e.g., CERES-Wheat, CCAM, EPIC, and others) and climate change scenarios.

2 Use field experiments or artificial climate chamber experiments.

Crop simulation modeling method is considered as most used method and is frequently used with climate change scenarios. Inputs like rainfall, soil, temperature, nutrition, evapotranspiration, the economic environment, atmospheric circulation, and carbon circulation plays an important role in applying models which make the method to use labor and increase the expense. In addition, uncertainties in parameter values substantially increase the uncertainty estimates for model projections. And researchers do not fully understand the mechanisms driving crop growth, this lack of understanding leads to prediction risk. Field experiments require more time and a larger budget than other approaches, but the results of field experiments are often more straight forward.

\section{Data and Methodology}

\subsection{Study Area}

Chakwal is located in Potohar Plateau at $32^{\circ} 55^{\prime} 49^{\prime \prime} \mathrm{N}$ $72^{\circ} 51^{\prime} 20^{\prime \prime} \mathrm{E}$ and an altitude of $498 \mathrm{~m}$ in Punjab province, Pakistan, with a total area of about $6,524 \mathrm{~km}^{2}$. Agriculture in Potohar region is largely dependent on weather conditions. The reported average annual rainfall for Chakwal is about $880 \mathrm{~mm}$. In summer weather is hot while in winter it is cold and dry. The average temperature during winter is $8^{\circ} \mathrm{C}$, which rises to $42^{\circ} \mathrm{C}$ during summer. The major crops are Wheat, Ground Nut, Sorghum, Rape/Mustard Seed, Millet (Bajra) and Gram. Wheat is grown on most of the land, which is then used for both commercial and personal purposes (Figure 1).

\subsection{Satellite Data}

Landsat 5 TM satellite images contains 7 bands: 3 visible bands, 2 NIR bands \& 1 MIR band having $30 \mathrm{~m}$ spatial resolution and 1 TIR band having $120 \mathrm{~m}$ spatial resolution.

Landsat 7 consist of 7 spectral bands with a spatial resolution of $30 \mathrm{~m}$ for Bands $1-5$, and 7 . The resolution for Band 8 (panchromatic) is $15 \mathrm{~m}$ while Band 6 collects both low and high gain (Bands 61 and 62, respectively) having 60 $\mathrm{m}$ spatial resolution (resampled to $30 \mathrm{~m}$ ) [6].

The land surface temperature is extracted using Landsat 5 
and 7 images using band 6 which is a thermal band with wavelength $10.40-12.50$ with a resolution of 120 meters * for Landsat 5 and 60 meters * for Landsat 7 (acquired, but both products are resampled to 30 meters). To determine the value of LST, radiometric image correction is required until the ToA Radiance stage, followed by calculation of land surface emissivity and finally calculation of land surface temperature. The data used are Landsat 5 satellite images for
1990-1999 and Landsat 7 for 2000-2015, the time of recording images taken from November to April each year. Time for data collection (November-April) was selected due to full cycle of wheat crop. As per study area climate and environment November is considered as sowing month and April is considered as harvesting month. Landsat data is freely available and can be downloaded from https://earthdata.nasa.gov.

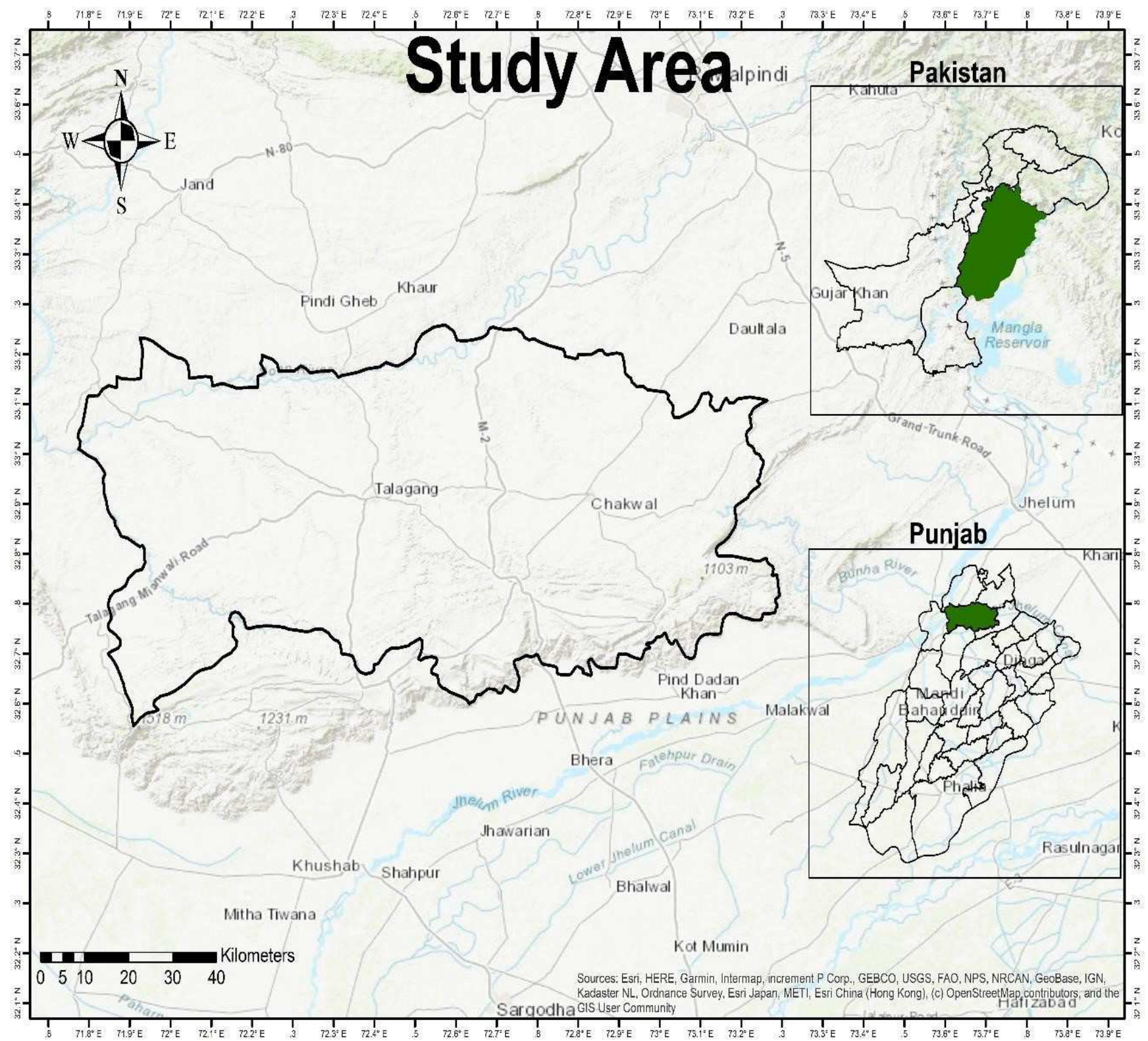

Figure 1. Study Area of study.

\subsection{Climatic Data}

Monthly precipitation, temperature, and humidity data for year 1990-2015 were obtained from Pakistan Metrological Department (PMD) station Chakwal. Crop yield data on annual basis were also obtained from PMD station Chakwal.

\section{Methodology}

Satellite data is used for image processing procedures in this study. Forecasting of crop yield is based on different type of data collected from different sources i.e. remotely sensed data and agriculture statistics. Figure 2 illustrates the steps applied to climate data and field data. Major input data sets as given 
below were gathered, compiled, and used.

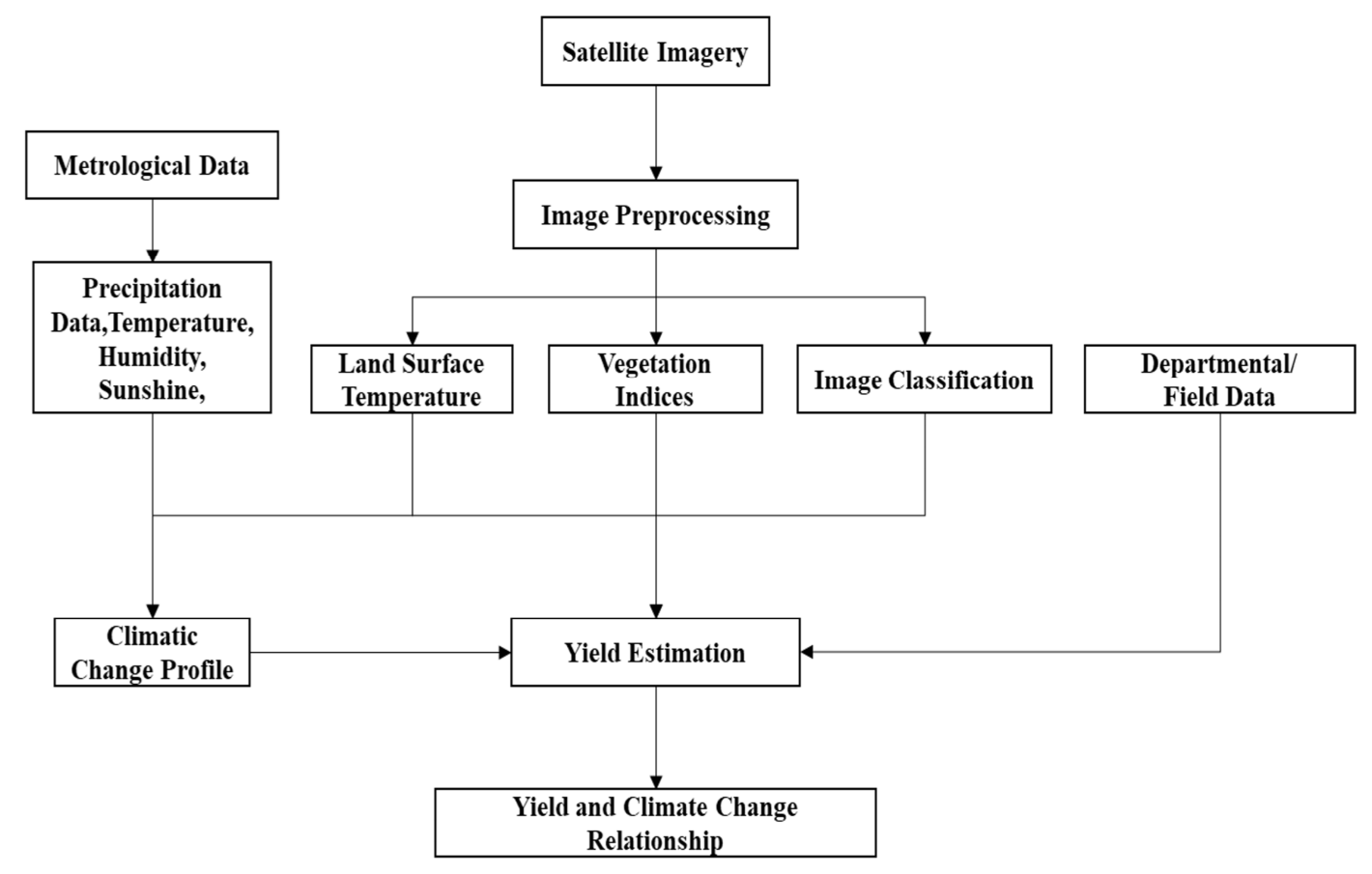

Figure 2. Methodology used for this study.

\subsection{Image Pre-Preprocessing}

Satellite imagery may have some errors due to acquisition by sensor or transmission to ground station which needs to be rectified before applying any analysis. These errors may include atmospheric, radiometric, and geometric calibrations depending upon the data. In addition to error removal some preprocessing of satellite data is necessary before performing any analysis. Preprocessing involved image stacking, mosaicking and subsetting the data as per study area.

Satellite sensor records the intensity of the ER for each pixel as a DN value, which can be converted to more meaningful real-world units like radiance or reflectance. Sensor specific information is required to carry out this calibration. Landsat Meta data file contains this information.

Atmospheric correction significantly improves the analysis and use of a satellite image which involves removal of the effects of atmosphere in the data and provide the surface reflectance values. This is a complex process requires knowledge of the atmospheric conditions and aerosol properties at the time the image was acquired. Different models are used to carry out atmospheric corrections, ENVI provides a convenient and effective model/ tool for atmospheric corrections "FLAASH"; which corrects wavelengths in the visible through near-infrared and shortwave infrared regions, up to $3 \mu \mathrm{m}$. Most of the parameters required for processing are available in image metadata file "MTL", including Date and Time of image acquisition, sensor type etc. Mean elevation of the image was provided using SRTM $30 \mathrm{~m}$ DEM. The atmospheric model for the study area is "Mid Latitude Summer" whereas "Urban" aerosol model was selected considering large urban settlements. Multispectral settings include KT Upper Channel, KT Lower Channel and
Cirrus Channel.

\subsection{Use of Landsat}

Landsat 7 ETM+ imagery acquired after May 2003 has the gap/ missing data, which required to be filled for RS \& GIS analysis. ENVI provides a tool "Landsat Gapfill" which can perform gap filling in data based on two layers with one layer having missing data and other having complete data. The tool can also fill in the missing data values using triangulation method on known values of the same single layer which was applied in this research. Though the gaps in the image are filled and remote sensing processes can be applied, however when the study area is more towards the left or right edges of the Landsat scene, the image has more of the interpolated values than of the real values and increases the possibility errors in image classification. Especially, Faisalabad district containing edges from four Landsat scenes and Multan district containing edges of the two Landsat scenes have larger gaps [7].

The land surface temperature is one of the important factors in wheat agricultural, therefore this variable needs to be included in the study regarding linear regression analysis that will be made between LST and NDVI. The land surface temperature is extracted using Landsat 5 and 7 images using band 6 which is a thermal band with wavelength $10.40-12.50$ with a resolution of 120 meters * for Landsat 5 and 60 meters * for Landsat 7 (acquired, but both products are resampled to 30 meters). To determine the value of LST, radiometric image correction is required until the ToA Radiance stage, followed by calculation of land surface emissivity and finally calculation of land surface temperature.

Multiband images for carrying out spatial analysis and band math operations like image differencing and radioing requires 
to form a composite image by stacking the different layers/ spectral bands, it is compulsory that all the band images which are to be stacked have the same spatial extent, projection and spatial resolution. Shape file from survey of Pakistan were used to crop the satellite imagery to study area extent [8].

\section{LULC Classification}

Supervised image classification technique was adopted to classify preprocessed images of the study area. Five classes (Agriculture Land, Bare land, Built-up areas, Grass land and wetlands) were extracted from satellite imagery. For every class fifteen (15) samples were collected and used as training samples. Supervised classification tool generates classified raster, these raster files were converted into classification vector as a shape file and then in the end statistics of every class has been calculated [9].

A widely used index is the normalized difference vegetation index (NDVI) as stated in Eq. 1 computed from the near infrared and red bands and proposed by Rouse (Ogilvie et al. 2015) to detect vegetation in images. This index can be used to detect water pixels, where it takes on negative values. NDVI raster can be used for identification and extraction different types of LULC:

\section{NDVI $=($ NIR band - Red band $) /($ NIR band + Red band $)$}

Value range for NDVI is between -1 to 1 . According to samples of study area the thresholds of NDVI for different LULC were set as; negative values belongs to water bodies and have range between -0.182 to -0.054 , bare lands has both positive and negative values and has a ranger between -0.082 to 0.138 , built-up areas having values in the range of -0.172 to 0.079 , vegetation only possess positive values and has a range of 0.151 to 0.521 and thick vegetation/ dense vegetation having values in the range of 0.293 to 0.615 .

Normalized difference built up index (NDBI) is often used to identify urban built-up areas. Near infrared (NIR) and shortwave infrared (SWIR) bands are used to compute NDBI as per given in eq. 2. Built-up areas gave higher reflectance in SWIR bands while have lowest reflectance in NIR band. Higher positive values of NDBI refers to build up areas.

$$
\mathrm{NDBI}=(\mathrm{SWIR}-\mathrm{NIR}) /(\mathrm{SWIR}+\mathrm{NIR})
$$

Vegetation classes were separated after NDVI and NDBI analysis for further extraction of wheat crop. Area for wheat crop were extracted through supervised classification by field samples and filed data of different years.

\section{Accuracy Assessment}

Accuracy assessment with an independent data set is the only way to determine the reliability of performed analysis. Different LULC can be easily distinguish by high resolution historic imagery provided by Google. Random point technique was used to assess the accuracy, separate random points for each year was taken and respective LULC class was assigned to each point according to classified raster image of same year. These random points were the converted to "KML". The "KML" file was loaded into "Google Maps Pro" and each point was compared with object / ground feature on the Google Pro image.

Estimation of wheat production requires information about planting area and rice productivity. Planting area in this study was obtained from the interpretation of remote sensing images. Wheat yield is obtained from the results of field surveys. Wheat production is calculated as yield for each pixel based on the model. Wheat yield result is the production of one planting season. Estimated wheat production in each pixel is added according to the area to know the estimated production in that area. Estimated wheat yield for the Chakwal region is calculated based on the total the number of pixel value, where the pixel value is containing yield estimation value. Meanwhile, the comparison between estimated wheat yield from satellite images and field survey are presented in Table 1.

Table 1. Accuracy Assessment Table.

\begin{tabular}{lll}
\hline Years & Area Accuracy\% & Yeild Accuracy \\
\hline Nov 1990- Apr 1991 & 98 & 87 \\
Nov 1995-Apr 1996 & 95 & 98 \\
Nov 2000-Apr 2001 & 85 & 93 \\
Nov 2005-Apr 2006 & 80 & 86 \\
Nov 2010-Apr 2011 & 78 & 85 \\
Nov 2014-Apr 2015 & 77 & 85 \\
\hline
\end{tabular}

\section{Results and Discussion}

This research applied remote sensing technology for temperature change and crop estimation in Chakwal districts. Remote sensing proved itself a very useful tool for the exact estimation of crop area and crop yield. Study linked the temperature and crop yield year by year. One of the goals of this study is estimating wheat yields using satellite imagery and their relationship with climate change. To achieve this goal, the data used are Landsat 5 satellite images for 1990-1999 and Landsat 7 for 2000-2015, detail of data acquisition date, tile, sensor and results from these images are given in Table 2.

Table 2. Table showing LST and crop estimation results.

\begin{tabular}{lllll}
\hline Satellite (Sensor) Tile & Acquisition Date & Minimum Temperature $\left({ }^{\circ} \mathbf{C}\right)$ & Maximum Temperature $\left({ }^{\circ} \mathbf{C}\right)$ & Crop Estimation Area $($ Hec) \\
\hline LT05_L1TP_150037 & $19 / 02 / 1990$ & -3.2 & 17.65 & 931 \\
LT05_L1TP_150037 & $01 / 02 / 1995$ & -3 & 20 & 14491 \\
LE07_L1TP_150037_ & $07 / 02 / 2000$ & -2.62 & 17.81 & 24188 \\
LE07_L1TP_150037 & $02 / 02 / 2010$ & -2.62 & 17.81 & 3796 \\
LLE07_L1TP_150037 & $15 / 01 / 2015$ & -2.37 & 18.34 & 40901 \\
\hline
\end{tabular}




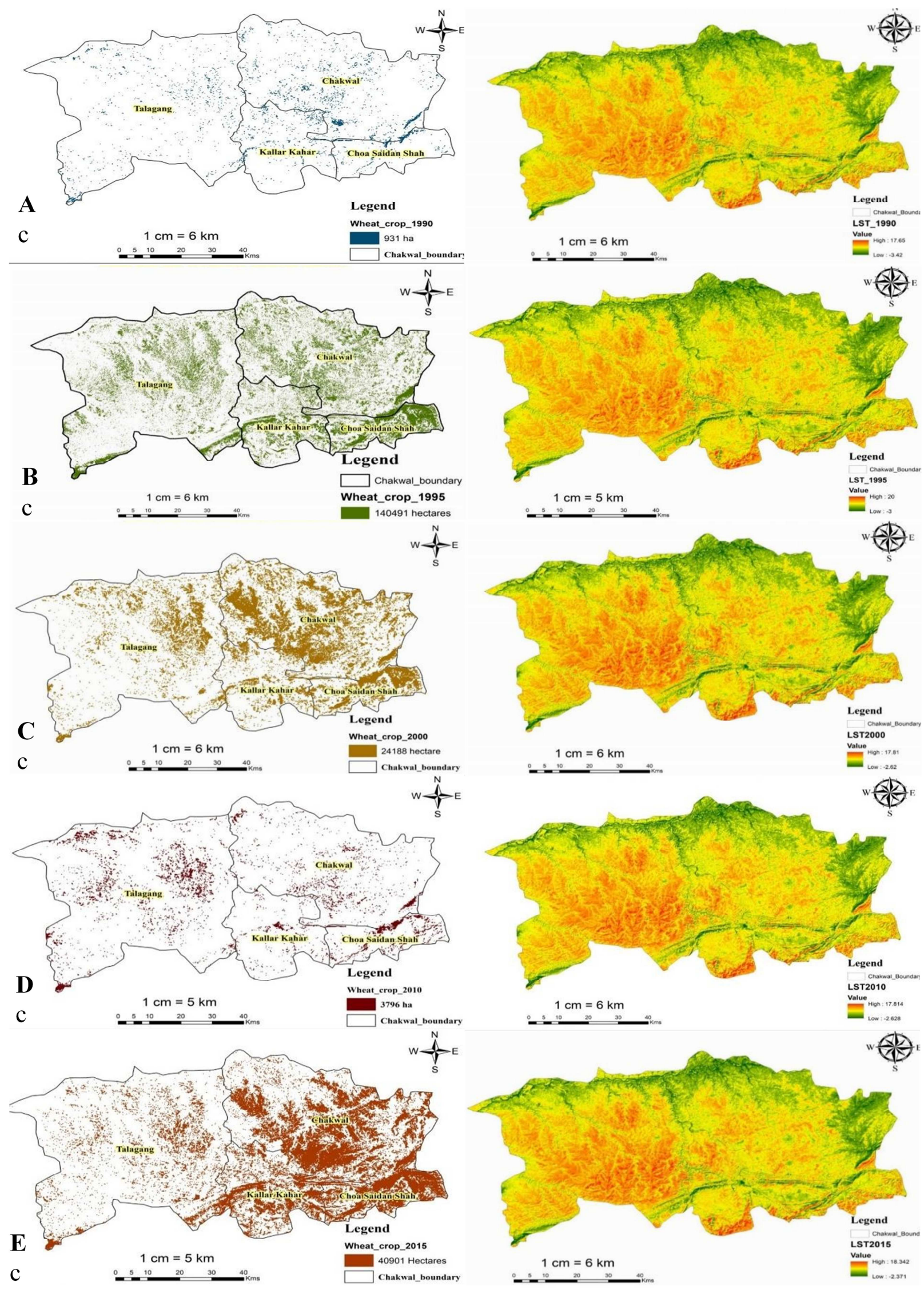

Figure 3. Figure Showing Crop area and LS T distribution for Chakwal.

LST from year 1990 to year 2010 were calculated from Landsat imagery. LST of 1990 showed the uprising 
temperature in the North western part of Chakwal. Highest temperature for given date was 17.65 and the minimum was 3.2. Wheat crop of district Chakwal has been calculated using satellite imagery by using NDVI and classification technique. Most of our study area consist of has agricultural land or baren land. Total wheat crop of the area has been calculated in hectares. Chakwal district has 931 hectares wheat crop during year 1990. Tehsil Chakwal has high wheat crop area and tehsil Talagang has lowest wheat crop area [10]. LST distribution and wheat crop distribution for year 1990 was shown in Figure 3A. LST of years 1995 with legend values of temperature from high to low in district Chakwal. The highest temperature is $20 \mathrm{C}$ and lowest is -3 . The lowest temperature is in vegetated areas. Highest temperature was recorded 20 in tehsil Talagang of district Chakwal which is consist of desert. Total area for wheat in year 1995 of district Chakwal was 14491 hectares. Tehsil Choa saidan shah has highest area value during this year, lowest wheat crop area has been analyzed in Tehsil Talagang. Tehsil Chakwal also shows higher values (Figure 3B). LST for 2000 showed the highest temperature is $17.81^{\circ} \mathrm{C}$ and lowest is $-2.62^{\circ} \mathrm{C}$. Total wheat crop area for year 2000 of district Chakwal was recorded as 24188 hectares. Tehsil Chakwal and Tehsil Choa saidan shah have higher ratio while Tehsil Talagang remained the lowest (Figure 3C). LST 2010 showed almost same values as year 2000 with highest temperature is $17.814^{\circ} \mathrm{C}$ and lowest is $-2.628^{\circ} \mathrm{C}$. Total wheat area in year 2010 of district Chakwal has area 3796 hectares. This year tehsil Talagang showed an improvement and significantly improve in wheat crop area (Figure 3D). Figure 3E showing the LST distribution for year 2015 with highest temperature is $18.342^{\circ} \mathrm{C}$ and lowest is $-2.371^{\circ} \mathrm{C}$. Total wheat crop area in 2015 of district Chakwal has area 40901 hectares. Tehsil Chakwal, Tehsil Choa saidan shah and Tehsil Kallar Kahar have higher yields while Tehsil Talagang has the lowest yields.

\section{Conclusion}

Remote Sensing science is widely adopted technology all over the world for crop yield estimation. In Pakistan, remote sensing technology still has very limited use for crop yield estimation and relation of climatic factors with crop yield. In this study we tried the potential use of Landsat imageries of different years for the identification of Wheat crop and LST in District Chakwal. Atmospheric Correction (Geometric Correction and Radiometric Calibration), NDVI for Wheat crop had been performed. Wheat crop area in hectares also calculated using raster to polygon and by calculates geometry. Ground truthing had been performed in five tehsils of District Chakwal during recent years which seems to be $85 \%$ to $90 \%$ accurate. Results accuracy proved the vital importance of remote sensing in crop estimation. LST trends has been also analyzed and relate with wheat crop area. LST from Landsat imagery was compared with metrological stations data. Comparison showed that LST can be used in that specific area instead of filed station data. Yield estimation analyzed from multiple imagery and LST shows that an increase in LST can improve the wheat crop in Chakwal. This methodology can be useful for the Agriculture department for the food policy in Chakwal.

\section{References}

[1] Ahamad, M. I., Zafar, Z., Arsalan, M., Rehman, A., Sajid, M., Zulqarnain, R. M., Mehmood, M. S., Abdal, S., Aslam, M., 2020. Effects of Temperature and Pressure on Reservoir Fluids and Seismic Properties of Reservoir Rocks. Int. J. Pharm. Sci. Rev. Res. 63, 36-43.

[2] Ahamad, Song, Sun, Wang, Mehmood, Sajid, Su, Khan, 2020. Contamination Level, Ecological Risk, and Source Identification of Heavy Metals in the Hyporheic Zone of the Weihe River, China. Int. J. Environ. Res. Public Health 17, 1070. https://doi.org/10.3390/ijerph17031070

[3] Ahemad \& Kibert 2014. Crop Phenological Phase based Wheat yield estimation using MODIS NDVI Product. PhD Thesis, Islamabad.

[4] Ahmad, W., Noor, M. A., Afzal, I., Bakhtavar, M. A., Nawaz, M. M., Sun, X., Zhou, B., Ma, M., Zhao, M., 2016. Improvement of Sorghum Crop through Exogenous Application of Natural Growth-Promoting Substances under a Changing Climate. Sustainability. 8, 1330; http://dx.doi.org/10.3390/su8121330

[5] Baig, M. B., Straquadine, G., 2011. "Sustainable agriculture ensures sustainable ruraldevelopment: a reality or a myth". In: M. Behnassi et al. (Eds.), Global food insecurity: rethinking agricultural and rural development paradigm and policy, pp. 21-32. http://dx.doi.org/10.1007/978-94-007-0890-7_3, Springer Science +Business Media B. V.

[6] Government of Pakistan, 2015. Ministry of Finance. Pakistan economic survey 2015-16. pp. 5-8.

[7] Noor, M. A., Ahmad, W., Afzal, I., Salamh, A., Afzal, M., Ahmad, A., Ming, Z., Wei, M., 2016. Pea seed invigoration by priming with magnetized water and moringa leaf extract. Philipp. Agric. Sci 99, 171-175.

[8] Noor, M. A., Fiaz, S., Nawaz, A., Nawaz, M. M., 2018. The effects of cutting interval on agro-qualitative traits of different millet (Pennisetum americanum L.) cultivars. J. Saudi Soc. $\begin{array}{llll}\text { Agric. } & \text { Sci. } & 17 & \text { (3), }\end{array}$ http://dx.doi.org/10.1016/j.jssas.2016.07.002

[9] Reynolds, C. A., Yitayew, M., Slack, D. C., Hutchison, C. F., Huete, A., \& Peteresen, M. S. (2000). Estimating crop yields and production by intergratingthe FAO crop specific Water Balance model with real-time satellite data and ground based ancilliary data. International Journal of Remote Sensing, $348=$ ' 7 7-3508.

[10] Waqas, M. A., Khan, I., Akhter, M. J., Noor, M. A., Ashraf, U., 2017. Exogenous application of plant growth regulators (PGRs) induces chilling tolerance in short-duration hybrid maize. Environ. Sci. Pollut. Res. 24, 11459-11471.

[11] Zafar, S. A., Hameed, A., Khan, A. S., Ashraf, M., 2017. Heat shock induced morphophysiological response in indica rice (Oryza sativa L.) at early seedling stage. Pak. J. Bot. 49 (2), 453-463. 